\title{
Effect of $\mathrm{OH}$ emission on the temperature and wind measurements derived from limb-viewing observations of the $1.27 \mu \mathrm{m} \mathrm{O}_{2}$ dayglow
}

\author{
Kuijun Wu${ }^{1}$, Weiwei $\mathrm{He}^{2}$, Yutao Feng ${ }^{3}$, Yuanhui Xiong ${ }^{1}$, and Faquan $\mathrm{Li}^{1}$ \\ ${ }^{1}$ State Key Laboratory of Magnetic Resonance and Atomic and Molecular Physics, Wuhan Institute of Physics and \\ Mathematics, Chinese Academy of Sciences, Wuhan National Laboratory for Optoelectronics, Wuhan 430071, China \\ ${ }^{2}$ City College, Wuhan University of Science and Technology, Wuhan, Hubei 430083, China \\ ${ }^{3}$ Key Laboratory of Spectral Imaging Technology of Chinese Academy of Sciences, Xi' an Institute of Optics and Precision \\ Mechanics, Chinese Academy of Sciences, Xi'an 710119, China
}

Correspondence: Kuijun Wu (wukuijun@wipm.ac.cn)

Received: 13 June 2019 - Discussion started: 17 June 2019

Revised: 8 February 2020 - Accepted: 5 March 2020 - Published: 8 April 2020

\begin{abstract}
The $\mathrm{O}_{2}\left(\mathrm{a}^{1} \Delta_{\mathrm{g}}\right)$ emission near $1.27 \mu \mathrm{m}$ is wellsuited for remote sensing of global wind and temperature in near-space by limb-viewing observations to its bright signal and extended altitude coverage. However, vibrationalrotational emission lines of the $\mathrm{OH}$ dayglow produced by the hydrogen-ozone reaction $\left(\mathrm{H}+\mathrm{O}_{3} \rightarrow \mathrm{OH}^{\bullet}+\mathrm{O}_{2}\right)$ overlap the infrared atmospheric band emission $\left(\mathrm{a}^{1} \Delta_{\mathrm{g}} \rightarrow X^{3} \Sigma_{\mathrm{g}}\right)$ of $\mathrm{O}_{2}$. The main goal of this paper is to discuss the effect of $\mathrm{OH}$ emission on the wind and temperature measurements derived from the $1.27 \mu \mathrm{m} \mathrm{O}_{2}$ dayglow limb-viewing observations. The $\mathrm{O}_{2}$ dayglow and $\mathrm{OH}$ dayglow spectrum over the spectral region and altitude range of interest is calculated by using the line-by-line radiative transfer model and the most recent photochemical model. The method of four-point sampling of the interferogram and sample results of measurement simulations are provided for both $\mathrm{O}_{2}$ dayglow and $\mathrm{OH}$ dayglow. It is apparent from the simulations that the presence of $\mathrm{OH}$ dayglow as an interfering species decreases the wind and temperature accuracy at all altitudes, but this effect can be reduced considerably by improving $\mathrm{OH}$ dayglow knowledge.
\end{abstract}

\section{Introduction}

The infrared atmospheric band emission $\left(\mathrm{a}^{1} \Delta_{\mathrm{g}} \rightarrow X^{3} \Sigma_{\mathrm{g}}\right)$ of $\mathrm{O}_{2}$ observed near the wavelength of $1.27 \mu \mathrm{m}$ has remarkable advantages in atmospheric remote sensing due to its bright signal and extended altitude coverage (Mlynczak et al., 2007). The enormous success of the Wind Imaging Inter- ferometer (WINDII) (Shepherd et al., 2012), high-resolution Doppler imager (HRDI) (Ortland et al., 1996) and TIMED Doppler interferometer (TIDI) (Killeen et al., 2006), which measured winds in the upper mesosphere and lower thermosphere using Doppler shifts in visible airglow emission lines, stimulates interest in measuring wind and temperature from limb-viewing satellites using the $1.27 \mu \mathrm{m}$ dayglow (Wu et al., 2018).

Ward et al. (2001) designed a high-sensitivity interferometer, WAMI, to provide simultaneous measurements of horizontal wind and rotational temperature by using the combination of a "strong" emission line group and a "weak" group of the $\mathrm{O}_{2}\left(\mathrm{a}^{1} \Delta_{\mathrm{g}}\right)$ airglow. A similar instrument, MIMI, designed by York University, also takes advantage of strong and weak emission lines for dynamics and thermodynamics measurement. Both WAMI and MIMI are imaging, fieldwidened Michelson interferometers and the same measurement technique, known as Doppler Michelson imaging interferometry, is employed successfully by the WINDII instrument on NASA's UARS satellite (Shepherd et al., 2012). The observing strategy of using two sets of three emission lines (as shown in Fig. 1 of Ward et al., 2001) makes it a perfect approach for WAMI and MIMI to improve our knowledge of the wind and temperature of the lower thermosphere and middle atmosphere, as well as global distribution and transport of $\mathrm{O}_{3}$. In recent years, measuring wind and temperature in the planetary atmosphere of Mars and Venus, for example, was also proposed by using a $1.27 \mu \mathrm{m}$ band emission of the electronically excited $\mathrm{O}_{2}\left(\mathrm{a}^{1} \Delta_{\mathrm{g}}\right)$ state (Ward et 
al., 2002; Zhang et al., 2017). Closely following the WAMI concept, we recently proposed a near-space wind and temperature sensing interferometer (NWTSI) for simultaneous measurements of the atmospheric wind and temperature in the near-space from the limb-viewing satellite by observing the $\mathrm{O}_{2}\left(\mathrm{a}^{1} \Delta_{\mathrm{g}}\right)$ dayglow near $1.27 \mu \mathrm{m}$ (He et al., 2019).

The strategy of choosing two sets of three emission lines adopted by WAMI, MIMI and NWTSI is quite ingenious. Three emission lines of each group are relatively well separated and belong to different branches within the same band, which allows them to be optically isolated and ensures distinct temperature sensitivities. Additionally, the line strengths of the strong group and the weak one differ by about 1 order of magnitude, so their radiation intensities and absorption characteristics varying with altitude are available for covering a great extended altitude range from 45 to $100 \mathrm{~km}$.

However, vibrational-rotational emission lines of the $\mathrm{OH}$ dayglow produced by the hydrogen-ozone reaction $(\mathrm{H}+$ $\mathrm{O}_{3} \rightarrow \mathrm{OH}^{\bullet}+\mathrm{O}_{2}$ ) overlap the infrared atmospheric band emission $\left(\mathrm{a}^{1} \Delta_{\mathrm{g}} \rightarrow X^{3} \Sigma_{\mathrm{g}}\right)$ of $\mathrm{O}_{2}$ near $1.27 \mu \mathrm{m}$ (Maihara et al., 1993), which may potentially contribute to the increase in wind and temperature errors.

The main goal of this paper is to discuss the effect of $\mathrm{OH}$ emission on the wind and temperature measurements derived from the $1.27 \mu \mathrm{m} \mathrm{O}_{2}$ dayglow limb-viewing observations. The atmospheric radiance model is simulated using a line-byline radiative transfer method. A brief description of the $\mathrm{O}_{2}$ dayglow and $\mathrm{OH}$ dayglow spectrum over the spectral region and altitude range of interest is provided. The forward simulation including instrument model and the method of fourpoint sampling of the interferogram, as well as sample results of measurement simulations, is presented. Inversion errors of wind and temperature measurements due to the effect of $\mathrm{OH}$ dayglow are presented and discussed. Here we report, to the best of our knowledge, the first consideration and discussion of the effect of $\mathrm{OH}$ dayglow on the temperature and wind measurements using the $1.27 \mu \mathrm{m} \mathrm{O}_{2}$ dayglow.

\section{$2 \mathrm{O}_{2}$ and $\mathrm{OH}$ dayglow spectrum}

\subsection{The $\mathrm{O}_{2}\left(\mathrm{a}^{1} \Delta_{\mathrm{g}}\right)$ and $\mathrm{OH}$ dayglow volume emission rates}

Two predominant mechanisms, the photolysis of $\mathrm{O}_{3}$ and the energy transfer from $\mathrm{O}\left({ }^{1} \mathrm{D}\right)$, produce the lowest-lying electronic state of molecular oxygen $\mathrm{O}_{2}\left(\mathrm{a}^{1} \Delta_{\mathrm{g}}\right)$ in the mesosphere and lower thermosphere. $\mathrm{O}_{2}\left(\mathrm{a}^{1} \Delta_{\mathrm{g}}\right)$ radiates strong emission in the infrared atmospheric band $\mathrm{O}_{2}\left(\mathrm{a}^{1} \Delta_{\mathrm{g}}\right) \rightarrow$ $\mathrm{O}_{2}\left(X^{3} \Sigma_{\mathrm{g}}\right)$ and produces dayglow at $1.27 \mu \mathrm{m}$. The volume emission rate (VER, defined as the number of photons emitted from a cubic centimeter per second) of a $\mathrm{O}_{2}$ individual rotational line can be given by (Mlynczak et al., 1993)

$$
\begin{array}{r}
\eta_{\mathrm{O}_{2}, \text { rot }}=A \frac{g^{\prime}}{Q_{\mathrm{O}_{2}}(T)} \exp \left(\frac{-h c E^{\prime}}{k T}\right) \\
\frac{\phi_{\alpha} R_{1}\left[\mathrm{O}_{3}\right]+\sum_{i=1}^{5} K_{i}\left[Y_{i}\right] \frac{\left[\mathrm{O}_{2}\right]\left\{R_{2}+\phi_{\eta} R_{3}\left[\mathrm{O}\left({ }^{1} \mathrm{D}\right)\right]\right\}}{A_{\mathrm{O}_{2}\left(\mathrm{~b}^{1} \Sigma_{\mathrm{g}}\right)}+\sum_{i=1}^{5} K_{i}\left[Y_{i}\right]}}{A_{\mathrm{O}_{2}\left(\mathrm{a}^{1} \Delta \mathrm{g}\right)}+\sum_{i=1}^{3} C_{i}\left[X_{i}\right]},
\end{array}
$$

where $A$ is the Einstein coefficient of the transition, $g^{\prime}$ is the upper state degeneracy, $Q(T)$ is the rotational partition function, $h$ is the Planck constant, $c$ is the light speed, $k$ is the Boltzmann constant, $T$ is the rotational temperature, $E^{\prime}$ is the upper state energy, $X=\left\{\mathrm{O}_{2}, \mathrm{~N}_{2}, \mathrm{O}\right\}, Y=$ $\left\{\mathrm{N}_{2}, \mathrm{O}_{2}, \mathrm{CO}_{2}, \mathrm{O}_{3}, \mathrm{O}\right\}, R_{1}=8.1 \times 10^{-3}, R_{2}=5.35 \times 10^{-9}$, $R_{3}=3.2 \times 10^{-11} \exp (70 / T) C_{1}=3.6 \times 10^{-18} e^{-220 / T}, C_{2}=$ $1.0 \times 10^{-20}, C_{3}=1.3 \times 10^{-16}, K_{1}=2.1 \times 10^{-15}, K_{2}=4.2 \times$ $10^{-13}, K_{3}=2.2 \times 10^{-11}, K_{4}=8.0 \times 10^{-14}, K_{5}=3.9 \times$ $10^{-17}$ and $0.54<\phi_{\eta}<1.0$.

An enhanced concentration of $\mathrm{OH}^{*}$ in high states occurs in a thin layer near the mesopause due to the hydrogenozone reaction, $\mathrm{H}+\mathrm{O}_{3} \rightarrow \mathrm{OH}^{*}+\mathrm{O}_{2}$. A multitude of excited $\mathrm{OH}^{*}$ in high vibrational and rotational states cascading to lower energy states results in an emission spectrum, which extends over a wide wavelength range $(500-5000 \mathrm{~nm})$. Among those vibrational-rotational transitions, two emission lines, $\mathrm{RR}_{2.5 e}$ and $\mathrm{RR}_{2.5 f}$ of the $\mathrm{OH}\left(X^{2} \Pi_{3 / 2}, v^{\prime}=8\right) \rightarrow$ $\mathrm{OH}\left(X^{2} \Pi_{3 / 2}, v^{\prime \prime}=5\right)$ band, are very close to the three weak target emission lines of the $1.27 \mu \mathrm{m} \mathrm{O}_{2}$ dayglow.

The volume emission rate of the $\mathrm{OH}(8-5)$ vibrational band can be given by (Russell and Lowe, 2003)

$$
\begin{aligned}
& \eta_{\mathrm{OH}, 8-5}\left(J^{\prime}, J^{\prime \prime}\right)=2\left(2 J^{\prime}+1\right) \\
& \quad \frac{[\mathrm{OH}(v=8)] A_{8-5}^{J^{\prime}, J^{\prime \prime}}}{Q_{\mathrm{OH}}(T)} \exp \left(-\frac{h c F_{8-5}\left(J^{\prime}\right)}{k T}\right),
\end{aligned}
$$

where $[\mathrm{OH}(v=8)]$ is the number density of $\mathrm{OH}$ in the $v=$ 8 state, $A_{8-5}^{J^{\prime}, J^{\prime \prime}}$ is the particular Einstein coefficient for the rotation transition of the (8-5) vibrational band, $J^{\prime}$ and $J^{\prime \prime}$ are initial and final values of the total angular momentum of the transition, and $F_{8-5}\left(J^{\prime}\right)$ is the upper state rotational term value.

Figure 1 shows the VER profiles of both the three weak target emission lines of the $1.27 \mu \mathrm{m} \mathrm{O}_{2}$ dayglow and the two emission lines, $\mathrm{RR}_{2.5 e}$ and $\mathrm{RR}_{2.5 f}$ of the $\mathrm{OH}\left(X^{2} \Pi_{3 / 2}, v^{\prime}=\right.$ $8) \rightarrow \mathrm{OH}\left(X^{2} \Pi_{3 / 2}, v^{\prime \prime}=5\right)$ band. As can be seen, the $\mathrm{O}_{2}$ dayglow peaks at about $45 \mathrm{~km}$ and the $\mathrm{OH}$ reaches $90 \mathrm{~km}$, and the emission rate of $\mathrm{O}_{2}$ is roughly 45 times stronger than $\mathrm{OH}$. In addition, the two emission lines of $\mathrm{OH}$ show a similar distribution profile over altitude, while the three emission lines of $\mathrm{O}_{2}$ differ a lot. This is because the two emission lines of $\mathrm{OH}$ share the same particular Einstein coefficient and total angular momentum, but the three emission lines of $\mathrm{O}_{2}$ are 
located in different vibration bands with sufficiently different lower-state energy, which leads to a disparity in temperature sensitivity.

\subsection{The $\mathrm{O}_{2}\left(\mathrm{a}^{1} \Delta_{\mathrm{g}}\right)$ and $\mathrm{OH}$ dayglow limb radiance}

In the case of limb-viewing, each viewing direction defines a ray path. The path segments defined by the intersection of atmospheric layers and ray paths is assumed to have the same emission and absorption characteristics. Evaluated on the layer-by-layer basis, the observed spectral irradiance is considered as a path integral along the line of sight (Song et al., 2017)

$L(v)=\int_{-\infty}^{\infty} \eta(s) D(v, s) \exp \left[-\int_{-s}^{\infty} n\left(s^{\prime}\right) \sigma\left(s^{\prime}\right) \mathrm{d} s^{\prime}\right] \mathrm{d} s$,

where $D(v)$ is the Doppler line shape of the spectral line, $\eta(s)$ is the volume emission rate, $n(s)$ is the number density, $\sigma(s)$ is the absorption cross section and $s$ is the distance along the line of sight.

Figure 2 shows the limb spectral radiance of three emission lines of $\mathrm{O}_{2}$ and the two emission lines of $\mathrm{OH}$ at different altitudes (40-90 km with $10 \mathrm{~km}$ interval). The inset panels show a magnified view of a certain emission line, from which the linewidth and intensity varying with tangent heights can be seen more clearly.

The total spectral irradiance including the weak group of the $\mathrm{O}_{2}$ dayglow and the $\mathrm{OH}$ dayglow is shown in Fig. 3a. The third emission line of the $\mathrm{O}_{2}$ dayglow near $7823 \mathrm{~cm}^{-1}$ is too close to the $\mathrm{OH}$ lines $\mathrm{RR}_{2.5 e}$ and $\mathrm{RR}_{2.5 f}$ (less than $0.05 \mathrm{~nm}$ ) to be well isolated optically. Figure $3 \mathrm{~b}$ shows the band radiance profiles of the $\mathrm{O}_{2}\left(\mathrm{a}^{1} \Delta_{\mathrm{g}}\right)$ near $7823 \mathrm{~cm}^{-1}$ and the $\mathrm{OH}$ dayglow, and their ratio. As can be seen, the $\mathrm{OH}$ dayglow affects the observation of the $\mathrm{O}_{2}$ emission line near $7823 \mathrm{~cm}^{-1}$, especially for altitudes between 80 to $90 \mathrm{~km}$ where the $\mathrm{OH}$ dayglow is relatively strong.

The Doppler shift of the emission line due to the movement of the atmosphere is measured as a phase shift of the Michelson interferometer, and accurate temperature measurement is obtained from the integrated absorbance ratio of two isolated emission lines (He et al., 2019). However, the intensity variation caused by Doppler shift or temperature change is very small. The relative Doppler shift is $w / c$, where $w$ denotes the motion of the background atmosphere and $c$ is the velocity of light. If winds are to be measured to an accuracy of $3 \mathrm{~m} \mathrm{~s}^{-1}$, a desirable value for the mesosphere and stratosphere, the measurement must be made to one part in $10^{8}$ of the velocity of light. For the central wavelength of $1270 \mathrm{~nm}$, that means the measurement of the wavelength shift is about $12 \mathrm{fm}$ (femtometer). Since a linewidth of the $\mathrm{O}_{2}$ dayglow is of the order of $0.003 \mathrm{~nm}$, the wavelength shift is $4 \times 10^{-3}$ of the linewidth. Therefore, the intensity variation of the band radiance near $7823 \mathrm{~cm}^{-1}$ caused by the existence of the $\mathrm{OH}$ dayglow will surely contribute to the increase in wind error, as well as the temperature error.

\section{Forward simulation}

\subsection{The instrument model}

The NWTSI, using the combination of a "strong" emission lines group and a "weak" group of the $\mathrm{O}_{2}\left(\mathrm{a}^{1} \Delta_{\mathrm{g}}\right)$ airglow, is a limb-viewing satellite instrument (He et al., 2019). The schematic drawing of the limb-imaging geometry and instrument concept is shown in Fig. 4, which closely follows the WAMI concept (Ward et al., 2001). The field of view (FOV) of NWTSI is defined by the first telescope with a value of $1.5^{\circ} \times 1.5^{\circ}$, which allows NWTSI to cover an entire altitude range from 20 to $120 \mathrm{~km}$ in single images for a nominal spacecraft altitude of $410 \mathrm{~km}$.

The entrance aperture of NWTSI is about $5 \mathrm{~cm}$ in diameter with an effective aperture ratio of $f / 1.3$. The magnifications of the first telescope and second are 2 and 0.5 respectively, so the FOV at the Michelson is $3^{\circ} \times 3^{\circ}$ and at the filters is again $1.5^{\circ} \times 1.5^{\circ}$. The beam splitter of the NWTSI fieldwidened Michelson interferometer consists of two cemented half-hexagons with a low-polarizing semi-reflecting dielectric multilayer on one of the diagonal faces. It is made of BK7 glass and the entrance and exit faces are $6.35 \mathrm{~cm}^{2}$. Large optical path difference (OPD) and field widening involve using $12.240 \mathrm{~cm}$ LaKN12 glass and $11.070 \mathrm{~cm}$ BK7 glass with corresponding refractive indices 1.733 and 1.516 in the two arms of the interferometer. The OPD between the paths of the two arms of the Michelson interferometer for normal incident can be found from $\Delta_{0}=2\left(n_{1} L_{1}-n_{2} L_{2}\right)$ (He et al., 2019), which corresponds to a value of $7.35 \mathrm{~cm}$. In order to avoid errors caused by intensity variations during measurements, the four interferogram samples are taken simultaneously rather than sequentially by dividing one Michelson mirror into four equal segments so the steps are coated permanently onto the mirror. A composite of etalon and interference filter is used to isolate individual emission lines. The etalon is fused silica with a finesse of 20 and a free spectral range of $2.0 \mathrm{~nm}$. The etalon thickness is designed to give optimum transmittance in the outer one-third of the field of view for three strong and three weak $\mathrm{O}_{2}$ emission lines. The imaging system produces four copies of FOV by using a shallow, pyramid-shaped prism just in front of the camera. The edges of the prism are aligned with the divisions between the quadrants of the sectored Michelson mirror to form four images on the array detectors simultaneously, corresponding to different sampling steps of the Michelson segments.

\subsection{The imaging interferogram}

By sampling the interferogram for each pixel at four points corresponding to the four phase steps, the Doppler wind is obtained, which is so called the four-point sampling method. The equation representing the interferogram for a given pixel at row $l$ and column $j$ of the detector is (Rahnama et 

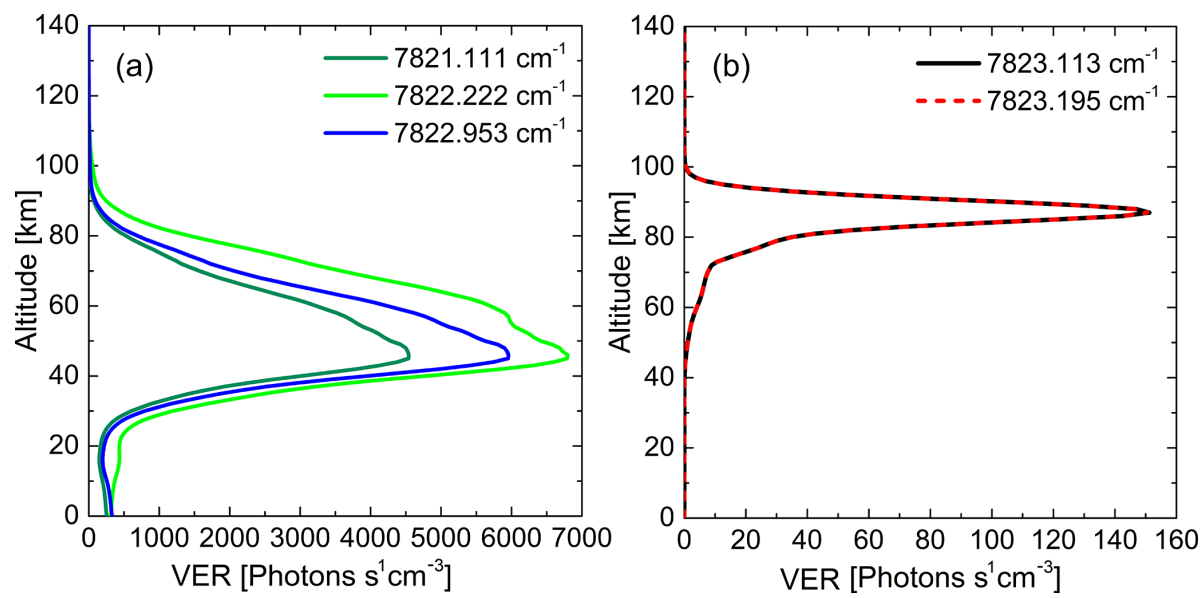

Figure 1. The VER profiles of both the three weak target emission lines of the $1.27 \mu \mathrm{m} \mathrm{O}_{2}$ dayglow and the two emission lines of $\mathrm{OH}$.

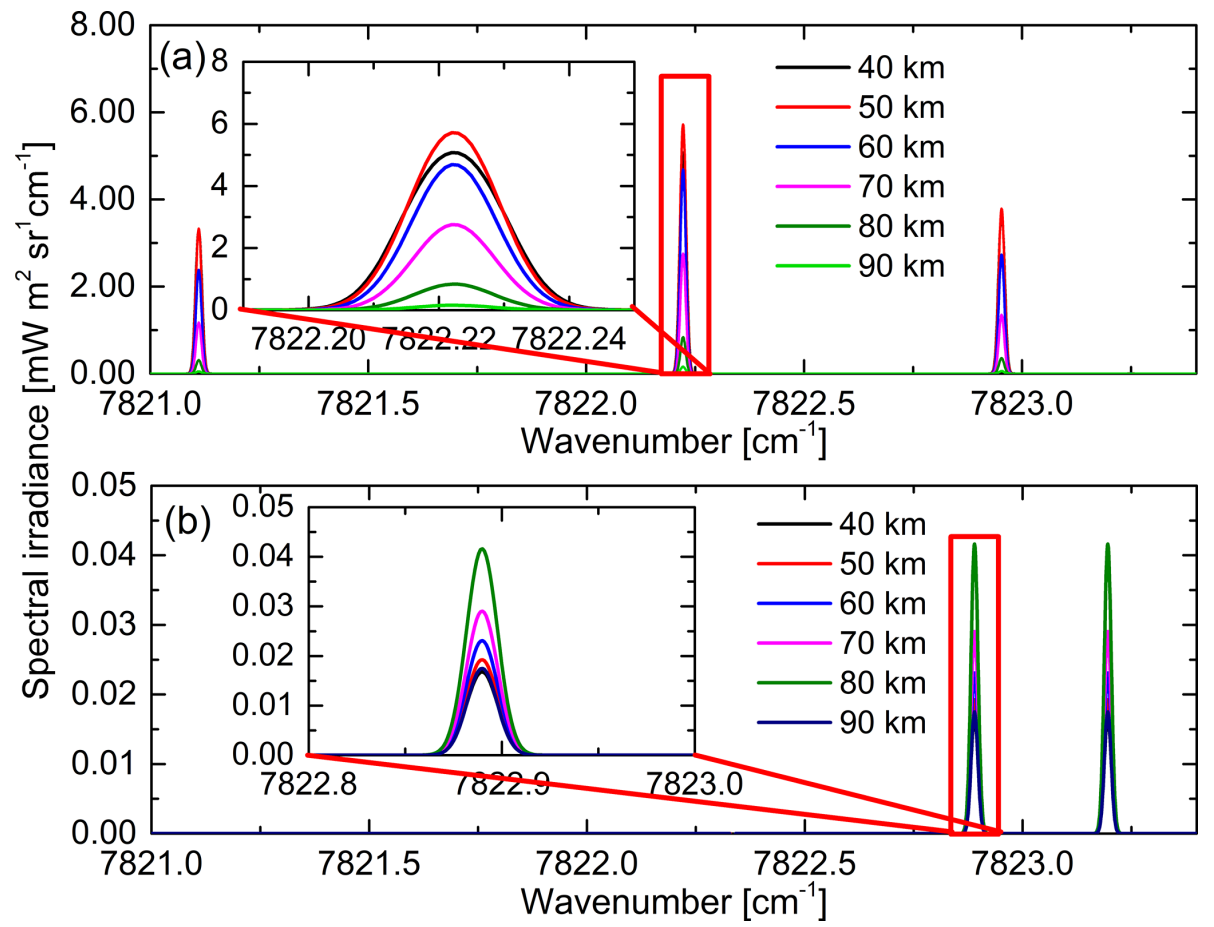

Figure 2. The spectral irradiance of the three emission lines of $\mathrm{O}_{2}$ dayglow and the two emission lines of $\mathrm{OH}$ dayglow at tangent heights of 40, 50, 60, 70, 80 and $90 \mathrm{~km}$. (a) Three emission lines of $\mathrm{O}_{2}$ dayglow. (b) Two emission lines of OH dayglow. The inset panels of (a) and (b) show a magnified view of a certain emission line of $\mathrm{O}_{2}$ and $\mathrm{OH}$ dayglow, from which the linewidth and intensity varying with tangent heights can be seen more clearly.

al., 2006)

$$
\begin{aligned}
I_{k l j} & =R_{l j} \int_{\nu_{1}}^{\nu_{2}} f_{l j}(v) \cdot L_{l j}(v) \\
& \cdot\left[1+U_{l j} \cos \left(2 \pi v \Delta_{l j}+\varphi_{k l j}\right)\right] \mathrm{d} v,
\end{aligned}
$$

where $f_{l j}(v)$ is the relative total filter function, $U_{l j}$ is the instrument visibility, $\Delta_{l j}$ is the OPD, $\varphi_{k l j}$ is the Michelson interferometer $k$ th phase step, and $\nu$ is the wavenumber; the instrument responsivity $R_{l j}$ is defined by

$R_{l j}=\frac{A \Omega t \tau q}{h c v_{0}}$,

where $A \Omega$ is the pixel etendue, $t$ is the exposure time, $\tau$ is the attenuation and $q$ is the quantum efficiency.

The simulated mean value of the interferogram for the weak group of $\mathrm{O}_{2}$ dayglow as well as the $\mathrm{OH}$ dayglow is shown in Fig. 5. The pattern in Fig. 5a reflects the varia- 

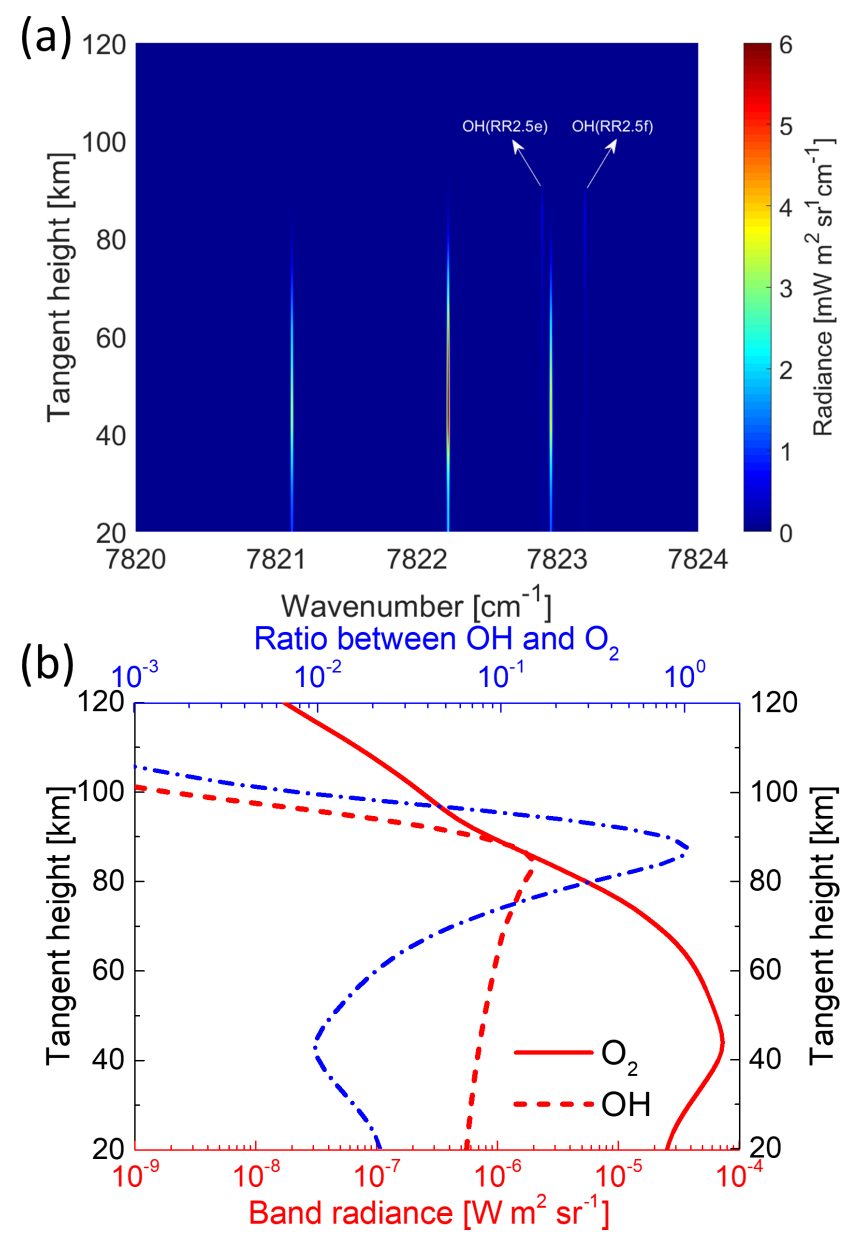

Figure 3. The total spectral irradiance and band radiance as a function of tangent height. (a) The total spectral irradiance containing $\mathrm{O}_{2}\left(\mathrm{a}^{1} \Delta_{\mathrm{g}}\right)$ and $\mathrm{OH}$ dayglow as a function of tangent height. (b) The band radiance profiles of the $\mathrm{O}_{2}\left(\mathrm{a}^{1} \Delta_{\mathrm{g}}\right)$ and $\mathrm{OH}$ dayglow and their ratio.

tion over the field of the filter transmittance function, the dependence of OPD on pixel positions and the tangent height variation of $\mathrm{O}_{2}$ dayglow within a column. The image in Fig. 5b shows the interference fringe of $\mathrm{OH}$ dayglow is much stronger for pixels nearer the periphery of the focal plane array (FPA), where the signal of the third weak emission line of the $\mathrm{O}_{2}$ dayglow near $7823 \mathrm{~cm}^{-1}$ is imaged.

\section{Inversion error due to the effect of $\mathrm{OH}$ dayglow}

Molecular species in NWTSI's selected spectral range of $7820-7824$ and $7908-7912 \mathrm{~cm}^{-1}$ other than $\mathrm{O}_{2}$ can affect NWTSI's wind and temperature measurements through absorption and emission. Limb spectral radiance of $\mathrm{OH}$ airglow is the most important interfering constituent for NWTSI, especially for the weak group detection, as shown in Figs. 3 and 5. Using etalon as the ultra-narrow filter significantly reduces but does not eliminate the influence from $\mathrm{OH}$ airglow. Therefore, the uncertainty in its mixing ratio surely contributes to the increase in wind and temperature errors. Note that while the fabrication of this ultra-narrow filter with a spectral width of $0.1 \mathrm{~nm}$ is feasible for current technical levels and engineering capability, it would be extremely challenging to monitor the changes in its width and central wavelength during the mission.

The wind velocity $v_{\mathrm{w}}$ is measured as a phase shift $\delta \varphi$ of the interferogram

$v_{\mathrm{w}}=\frac{c}{2 \pi \Delta v_{0}} \delta \varphi$,

and phase $\varphi$ can be calculated from

$\varphi_{t}=\tan ^{-1}\left(\frac{J_{3}}{J_{2}}\right)$.

Fourier coefficients, $J_{1}, J_{2}$ and $J_{3}$, also referred to as the apparent quantities, are related to any point $k$ along a fringe interferogram I (Shepherd et al., 2012):

$$
\begin{aligned}
& J_{1}=I_{\text {mean }}=\frac{1}{4} \sum_{k=1}^{4} I_{k}, \\
& J_{2}=\frac{1}{2 U} \sum_{k=1}^{4} I_{k} \cos \left(\varphi_{k l j}\right), \\
& J_{3}=\frac{1}{2 U} \sum_{k=1}^{4} I_{k} \sin \left(\varphi_{k l j}\right) .
\end{aligned}
$$

Omitting the presence of $\mathrm{OH}$ emission will change the value of $J_{2}$ and $J_{3}$, which will inevitably lead to an inversion error for the wind measurement.

The error standard deviation of inverted wind due to the presence of $\mathrm{OH}$ emission is found from the following relation (He et al., 2019):

$\sigma_{\nu}=c \frac{\sqrt{J_{2}^{2} \sigma_{J_{3}}^{2}+J_{3}^{2} \sigma_{J_{2}}^{2}}}{2 \pi v_{0} \Delta\left(J_{2}^{2}+J_{3}^{2}\right)}$,

where $\sigma_{J_{2}}^{2}$ and $\sigma_{J_{3}}^{2}$ represent the variance of the Fourier coefficients $J_{2}$ and $J_{3}$ due to the lack of knowledge on $\mathrm{OH}$ emission.

The contribution of $\mathrm{OH}$ dayglow to the wind error is shown in Fig. 6a. The black curve represents omitting the presence of the $\mathrm{OH}$ emission. As can be seen, the wind error is about $1-2 \mathrm{~m} \mathrm{~s}^{-1}$ for altitudes below $70 \mathrm{~km}$, climbing to greater than $8 \mathrm{~m} \mathrm{~s}^{-1}$ as the altitude increases from 80 to $90 \mathrm{~km}$. The sensitivity of wind retrieval is weaker in the lower altitudes due to the lower $\mathrm{OH}$ volume emission rate. The degree of knowledge of $\mathrm{OH}$ dayglow is important for NWTSI retrieval. The blue short-dash-dot line and the red short-dash line in Fig. 6a represent the error deviation of inverted wind with $\mathrm{OH}$ dayglow knowledge of $80 \%$ and $90 \%$, respectively. As can be seen, when $\mathrm{OH}$ dayglow is known to $80 \%$, the wind error is $0.3-0.5 \mathrm{~m} \mathrm{~s}^{-1}$ for the altitude range of 40-70 km; for $\mathrm{OH}$ dayglow knowledge of $90 \%$, the wind error decreases to $0.1-0.3 \mathrm{~m} \mathrm{~s}^{-1}$. 


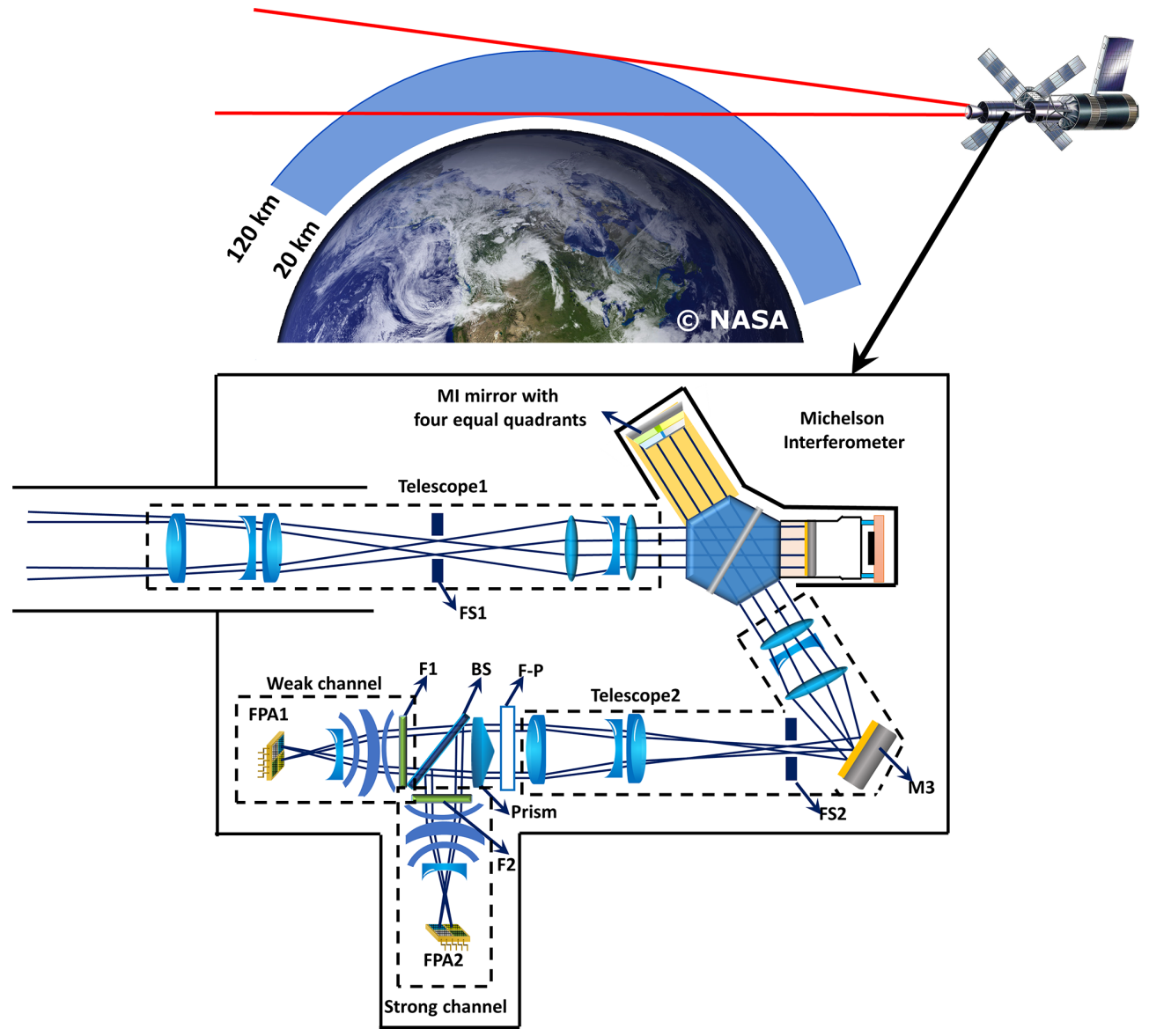

Figure 4. Limb-imaging geometry and optical concept schematic drawing for NWTSI. The background map is from @ NASA (https:// eoimages.gsfc.nasa.gov/images/imagerecords/57000/57723/globe_west_2048.jpg, last access: 12 February 2020).
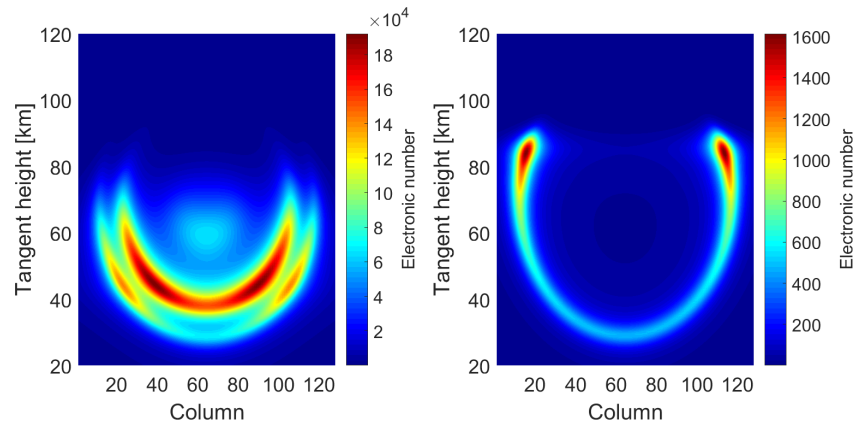

Figure 5. The simulated interferogram images of the weak $\mathrm{O}_{2}\left(\mathrm{a}^{1} \Delta_{\mathrm{g}}\right)$ and $\mathrm{OH}$ emission lines.

The error standard deviation of inverted temperature due to the presence of $\mathrm{OH}$ emission can be written as

$\sigma_{T}=\frac{\Delta T}{T}=\frac{R_{\mathrm{AB}}}{T} \frac{\mathrm{d} T}{\mathrm{~d} R_{\mathrm{AB}}} \sqrt{\sigma_{J_{1 \mathrm{~A}}}^{2}+\sigma_{J_{1 \mathrm{~B}}}^{2}}$,

where $\sigma_{J_{1 \mathrm{~A}}}^{2}$ and $\sigma_{J_{1 \mathrm{~B}}}^{2}$ represent the variance of the Fourier coefficients $J_{1}$ of two emission lines A and B of the weak group of the $\mathrm{O}_{2}$ dayglow, and $R_{\mathrm{AB}}$ is the ratio of the measured integral absorbances of this two lines, $R_{\mathrm{AB}}=J_{1 \mathrm{~A}} / J_{1 \mathrm{~B}}$.

A similar trend with the wind error is found for the temperature obtained from $J_{1 \mathrm{~A}}$ and $J_{1 \mathrm{~B}}$ : the temperature error is about $4-6 \mathrm{~K}$ for altitudes below $70 \mathrm{~km}$ and greater than $20 \mathrm{~K}$ for altitudes from 80 to $90 \mathrm{~km}$ (see the black curve in Fig. 6b). When $\mathrm{OH}$ dayglow is known to $80 \%$, the temperature error is $0.7-1.0 \mathrm{~K}$ for the altitude range of $40-70 \mathrm{~km}$ (see the blue short-dash-dot line in Fig. 6b); for $\mathrm{OH}$ dayglow knowledge of $90 \%$, the temperature error decreases to $0.3-0.5 \mathrm{~K}$ (see the red short-dash line in Fig. 6b).

By happy coincidence, the wind and temperature inversion for altitude above $70 \mathrm{~km}$ is irrelevant to the weak group. Due to their relative weak self-absorption effect, the weak emission lines are used only for wind and temperature measurement at low altitude. The three strong emission lines suffering little from self-absorption at relatively higher tangent heights take the place of the weak group for data inversion.

The performance analyses presented assume that the $\mathrm{OH}$ dayglow is known to a degree that results in meeting the threshold wind and temperature accuracies. The largest errors are obtained when not accounting for $\mathrm{OH}$ dayglow in 

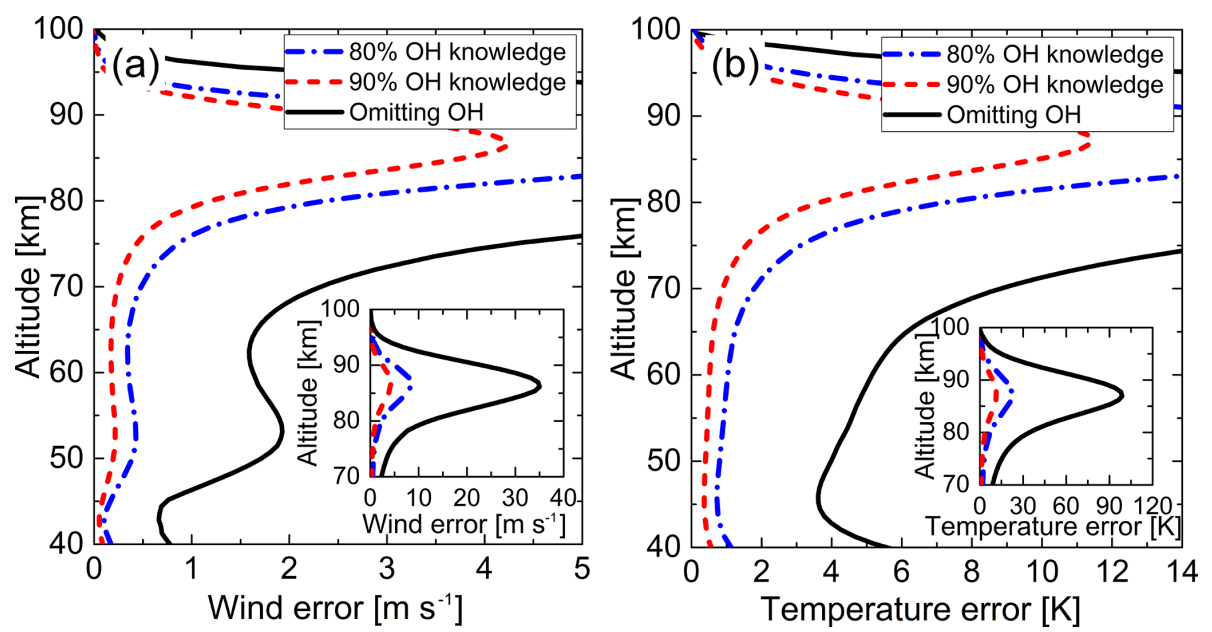

Figure 6. Inversion errors in wind and temperature due to omitting the presence of OH dayglow (black curve) and with $80 \%$ and $90 \%$ knowledge of the $\mathrm{OH}$ dayglow (blue short-dash-dot line and the red short-dash line). (a) The wind error profiles. (b) The temperature error profiles. The inset panels of (a) and (b) show the wind and temperature error in the altitude range 70-100 km.

the retrievals. In order to bring down the wind and temperature error to an acceptable level, $\mathrm{OH}$ dayglow knowledge with an accuracy of $80 \%-90 \%$ is required.

\section{Conclusions}

We have simulated and discussed the effect of $\mathrm{OH}$ dayglow on the wind and temperature measurements derived from the $1.27 \mu \mathrm{m} \mathrm{O}_{2}$ dayglow limb-viewing observations. We first calculated the $\mathrm{O}_{2}$ and $\mathrm{OH}$ dayglow spectrum over the spectral region and altitude range of interest using the line-by-line radiative transfer model and the photochemical model incorporating the most recent spectroscopic parameters, rate constants and solar fluxes. They show that the $\mathrm{OH}$ lines $\mathrm{RR}_{2.5 e}$ and $\mathrm{RR}_{2.5 f}$ are too close to the third weak emission line of the $\mathrm{O}_{2}$ dayglow near $7823 \mathrm{~cm}^{-1}$ (less than $0.05 \mathrm{~nm}$ ), which will surely affect the spectral integral intensity of the $\mathrm{O}_{2}$ mission line. A brief description of the instrument model of NWTSI including the schematic drawing of limbimaging geometry and the instrument concept is presented. The method of four-point sampling of the interferogram and sample results of measurement simulations are provided for both $\mathrm{O}_{2}$ and $\mathrm{OH}$ dayglow. It was apparent from the simulations that the interference fringe of $\mathrm{OH}$ dayglow is much stronger for pixels nearer the periphery of FPA, where the signal of the third weak emission line of the $\mathrm{O}_{2}$ dayglow near $7823 \mathrm{~cm}^{-1}$ is imaged. Inversion errors of wind and temperature measurements due to the effect of $\mathrm{OH}$ dayglow are presented and discussed in detail. The presence of $\mathrm{OH}$ dayglow as an interfering species decreases the NWTSI performance at all altitudes, with the largest impact for altitudes from 80 to $90 \mathrm{~km}$. The effect of OH dayglow on NWTSI inversion can be reduced by improving $\mathrm{OH}$ dayglow knowledge. Accurate $\mathrm{OH}(\mathrm{v}=8)$ concentrations (uncertainty level of $20 \%$ or better) are required to help meet the wind and temperature accuracy requirements.

Code availability. Available upon request.

Author contributions. KW and WH conceived the ideas, developed the forward model, performed the measurement simulation and wrote the manuscript. YF helped in the instrument conceptualization and error analysis. YX calculated the atmospheric limb radiance. FL provided optical design expertise knowledge. All the authors contributed to the analysis and discussion of the results.

Competing interests. The authors declare that they have no conflict of interest.

Acknowledgements. The authors gratefully acknowledge informative and helpful discussions with Wang Dingyi on theoretical details of this work.

Financial support. This research has been supported by the $\mathrm{Na}$ tional Natural Science Foundation of China (NSFC) (grant nos. 41975039 and 61705253) and the National Key R\&D Program of China (grant no. 2017YFC0211900).

Review statement. This paper was edited by Ad Stoffelen and reviewed by two anonymous referees. 


\section{References}

He, W., Wu, K., Feng, Y., Fu, D., Chen, Z., and Li, F.: The NearSpace Wind and Temperature Sensing Interferometer: Forward Model and Measurement Simulation, Remote Sens.-Basel, 11, 914, https://doi.org/10.3390/rs11080914, 2019.

Killeen, T. L., Wu, Q., Solomon, S. C., Ortland, D. A., Skinner, W. R., Niciejewski, R. J., and Gell, D. A.: TIMED Doppler Interferometer: Overview and recent results, J. Geophys. Res., 111, A10S01, https://doi.org/10.1029/2005JA011484, 2006.

Maihara, T., Iwamuro, F., Yamashita, T., Hall, D. N. B., Cowie, L. L., Tokunaga, A. T., and Pickles, A.: Observations of the OH airglow emission, Publ. Astron. Soc. Pac., 105, 940-944, https://doi.org/10.1086/133259, 1993.

Mlynczak, M. G., Solomon, S., and Zaras, D. S.: An updated model for $\mathrm{O}_{2}\left(\mathrm{a}^{1} \Delta_{\mathrm{g}}\right)$ concentrations in the mesosphere and lower thermosphere and implications for remote-sensing of Ozone at $1.27 \mu \mathrm{m}$, J. Geophys. Res., 98, 18639-18648, https://doi.org/10.1029/93JD01478, 1993.

Mlynczak, M. G., Marshall, B. T., Martin-Torres, F. J., Russell, J. M., Thompson, R. E., Remsberg, E. E., and Gordley, L. L.: Sounding of the Atmosphere using Broadband Emission Radiometry observations of daytime mesospheric $\mathrm{O}_{2}\left(\mathrm{a}^{1} \Delta_{\mathrm{g}}\right)$ $1.27 \mu \mathrm{m}$ emission and derivation of ozone, atomic oxygen, and solar and chemical energy deposition rates, J. Geophys. Res., 112, D15306, https://doi.org/10.1029/2006JD008355, 2007.

Ortland, D. A., Skinner, W. R., Hays, P. B., Burrage, M. D., Lieberman, R. S., Marshall, A. R., and Gell, D. A.: Measurements of stratospheric winds by the high resolution Doppler imager, J. Geophys. Res., 101, 10351-10363, https://doi.org/10.1029/95jd02142, 1996.

Rahnama, P., Rochon, Y. J., Mcdade, I. C., Shepherd, G. G., Gault, W. A., and Scott, A.: Satellite Measurement of Stratospheric Winds and Ozone Using Doppler Michelson Interferometry. Part I: Instrument Model and Measurement Simulation, J. Atmos. Ocean. Tech., 23, 753-769, https://doi.org/10.1175/JTECH1880.1, 2006.

Russell, J. P. and Lowe, R. P.: Atomic oxygen profiles (80$94 \mathrm{~km}$ ) derived from Wind Imaging Interferometer/Upper Atmospheric Research Satellite measurements of the hydroxyl airglow: 1. Validation of technique, J. Geophys. Res., 108, 4662, https://doi.org/10.1029/2003JD003454, 2003.
Shepherd, G. G., Thuillier, G., Cho, Y. M., Duboin, M. L., Evans, W. F. J., Gault, W. A., Hersom, C., Kendall, D. J. W., Lathuillere, C., Lowe, R. P., McDade, I. C., Rochon, Y. J., Shepherd, M. G., Solheim, B. H., Wang, D. Y., and Ward, W. E.: The Wind Imaging Interferometer (WINDII) on the Upper Atmosphere Research Satellite: A 20 Year Perspective, Rev. Geophys., 50, 713-723, https://doi.org/10.1029/2012RG000390, 2012.

Song, R., Kaufmann, M., Ungermann, J., Ern, M., Liu, G., and Riese, M.: Tomographic reconstruction of atmospheric gravity wave parameters from airglow observations, Atmos. Meas. Tech., 10, 4601-4612, https://doi.org/10.5194/amt-104601-2017, 2017.

Ward, W. E., Gault, W. A., Shepherd, G. G., and Rowlands, N.: The Waves Michelson Interferometer: A visible/near-IR interferometer for observing middle atmosphere dynamics and constituents, Proc. SPIE, 4540, 100-111, https://doi.org/10.1117/12.450652, 2001.

Ward, W. E., Gault, W. A., Rowlands, N., Wang, S., Shepherd, G. G., McDade, I. C., McConnell, J. C., Michelangeli, D., and Caldwell, J.: An imaging interferometer for satellite observations of wind and temperature on Mars, the Dynamics Atmosphere Mars Observer (DYNAMO), Proc. SPIE, 4833, 226-236, https://doi.org/10.1117/12.473823, 2002.

Wu, K. J., Fu, D., Feng, Y. T., Li, J., Hao, X. B., and Li, F. Q.: Simulation and application of the emission line $\mathrm{O}_{19} \mathrm{P}_{18}$ of $\mathrm{O}_{2}\left(\mathrm{a}^{1} \Delta_{\mathrm{g}}\right)$ dayglow near $1.27 \mu \mathrm{m}$ for wind observations from limb-viewing satellites, Opt. Express, 26, 16984-16999, https://doi.org/10.1364/OE.26.016984, 2018.

Zhang, R., Ward, W. E., and Zhang, C. M.: $\mathrm{O}_{2}$ nightglow snapshots of the $1.27 \mu \mathrm{m}$ emission at low latitudes on Mars with a static field-widened Michelson interferometer, J. Quant. Spectrosc. Ra., 203, 565-571, https://doi.org/10.1016/j.jqsrt.2017.08.009, 2017. 